\title{
Two Asymmetries in Population and General Normative Ethics
}

\author{
Mat Rozas
}

University of Santiago de Compostela, mat.rozas@usc.es

DOI: http://dx.doi.org/10.5324/eip.v15i1.3860

(cc) BY
Attribution 4.0 International License, which permits unrestricted use, distribution, and
reproduction in any medium, provided the original author and source are credited.

This paper examines a dilemma in reproductive and population ethics that can illuminate broader questions in axiology and normative ethics. This dilemma emerges because most people have conflicting intuitions concerning whether the interests of non-existent beings can outweigh the interests of existing beings when those merely potential beings are expected to have overall net-good or overall net-bad lives. The paper claims that the standard approach to this issue, in terms of exemplifying the conflict between Narrow Person-Affecting Views and Impersonal Views, is not correct. It argues that, instead, we can approach the issue through the distinction between Symmetrical and Asymmetrical Views about the relative importance of positive and negative value. The paper also claims that Asymmetrical Views provide the most intuitively satisfactory solution to the dilemma and can in addition be defended independently on further grounds.

Keywords: person-affecting views, impersonal views, symmetry, asymmetry

\section{Introduction}

Reproductive dilemmas can be important in both reproductive ethics and population ethics. In addition, they can also be important in illuminating other much broader issues in value theory and normative ethics. This paper examines one of these dilemmas, and shows how the discussion about the way it can be approached has consequences beyond reproductive or population ethics. It accomplishes this by considering, first, how we can approach a counter-intuitive trade-off concerning what seems to be the most acceptable solution to two thought experiments in reproductive ethics, in which we consider whether the interests of non-existent beings can outweigh the interests of existing beings when those merely potential beings may have good or bad lives. The paper explains why the standard way of approaching this issue, in terms of Person-Affecting and Impersonal Views, is inadequate. It argues that a different distinction, between Symmetrical and Asymmetrical Views, is the one that can best explain the different views held when assessing these thought experiments. Finally, the paper argues in favour of Asymmetrical Views, considering that they are the only ones that can solve this dilemma and that they might be the only satisfactory views able to solve other issues in ethics. 


\section{The dilemma: The Happy Child and The Wretched Child}

Depending on the situation, we might consider certain trade-offs between value and disvalue among different individuals as intuitive or counterintuitive. One case in which these trade-offs seem counterintuitive is

The Happy Child. A couple are deciding if they should have a child or not. They would be slightly worse off if they have the child. However, the child would have a life worth living which would not be possible unless this couple decided to procreate.

Figure 1. The Happy Child
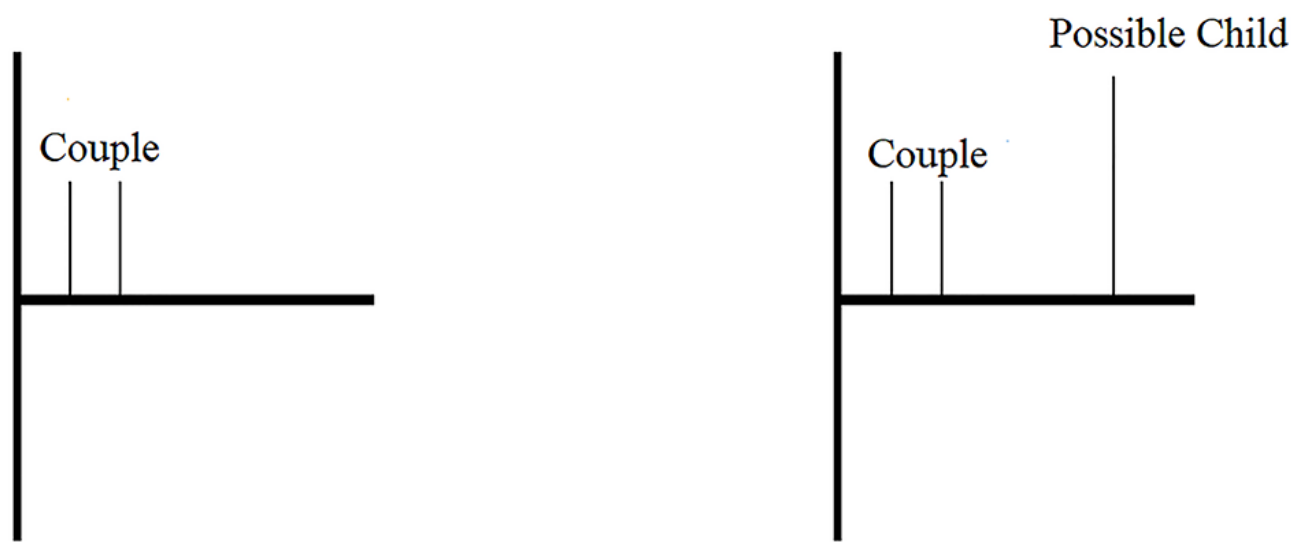

According to some views, the couple should have the child. This seems very counterintuitive to many. However, other views are neutral about making happy people, as they think that in a case like this, before the baby is conceived, the interests to take into account are those of the couple. This view notwithstanding, a similar case in which trade-offs of this type are clearly intuitive are ones in which disvalue affects some of the individuals involved. Consider

The Wretched Child. Another couple have decided to conceive a child. They will love and support their child the best they can and this will improve the lives of this couple. However, they know for certain that this child will be born impaired and that her life will be short and full of suffering. The total value of the outcome if the couple have the child will be smaller than the value of the outcome if they do not.

Figure 2. The Wretched Child
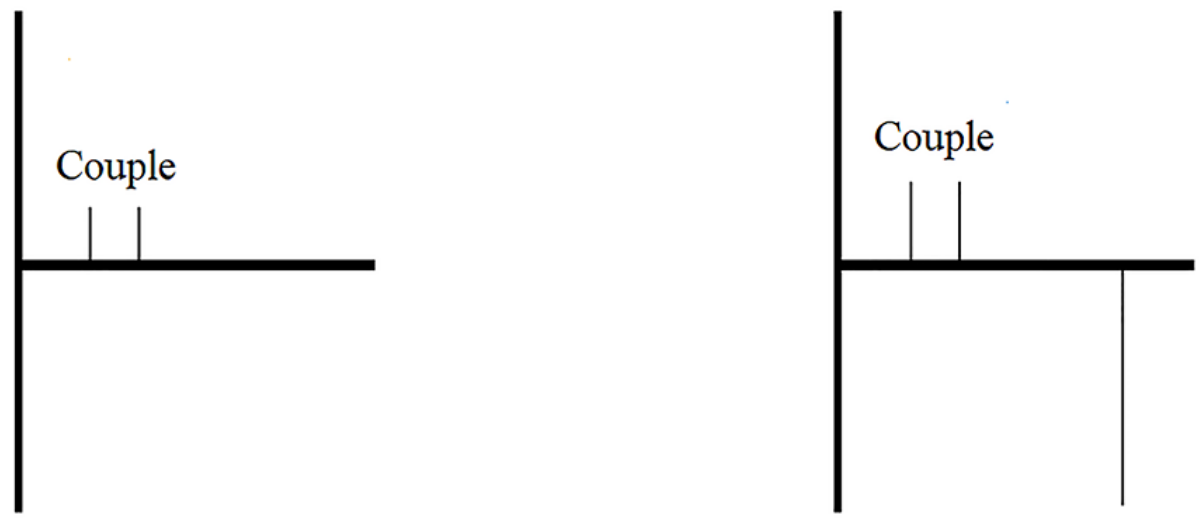

Possible Child 
The same views that contended that it was not better if the couple caused a blissful individual to exist in The Happy Child imply in this case that it is acceptable for the couple to conceive The Wretched Child. Yet in this case, it seems clearly intuitive that this couple ought not to conceive the child, given that the trade-off between the value for the couple and the disvalue for The Wretched Child would make the couple's decision seem regrettable. However, there is no way to reach this conclusion unless we reject the idea that only the interests of the couple should be taken into account in this decision. In spite of this, rejecting such a view leaves us with no reason to defend the most intuitive response to The Happy Child.

\section{Person-Affecting and Impersonal Views}

In the philosophical literature it is often assumed that this dilemma exemplifies the conflict between Narrow Person-Affecting Reasons and Impersonal Reasons. In order to acknowledge this, I will first examine what these positions claim.

Some views in population ethics assess outcomes by virtue of how they affect the interests of the individuals involved (Narveson 1973: 80). Among these views, the most commonly held ones are (Temkin 2014: 77) ${ }^{1}$

Narrow Person-Affecting Views: how good or bad an outcome is ought to be assessed by giving special consideration to how the particular individuals in those outcomes fare in comparison to how they fare in other alternative outcomes (Temkin 2014: 76).

These views are defended on different grounds. Temporal Person-Affecting Views claim that how good or bad an outcome is ought to be assessed by giving special consideration to some individuals by virtue of the moment in time in which the individuals are situated when assessing outcomes. The most common view of this kind (though not the only one) is probably Presentism, which claims that the interests of those who already exist (that is, those who exist in the present) should be prioritized over those who will exist later. Modal Person-Affecting Views evaluate outcomes by giving special consideration to some individuals by virtue of the type of modal existence that those individuals have when assessing outcomes. Actualism, for instance, claims that we should prioritize the existence of actual individuals instead of merely possible ones (Menzel 2018). Comparativism, another example of these views, claims that if certain individuals exist in more outcomes than others (that is, their existence is less contingent than other individuals' existence), the interests of those existing in more outcomes carry more weight.

These views can provide us with intuitive solutions in many cases, but the claim that we should only consider the interests of certain individuals is regarded as problematic by many people. Those who reject Narrow Person-Affecting Views might instead accept

Impersonal Views: how good or bad an outcome is ought not to be assessed based on how that situation affects the individuals involved. We should not give special consideration to some individuals over others.

It should be noted that Impersonal Views do not claim that individuals' interests do not matter. They do not need to accept a non-welfarist account, according to which entities that are not valuable for individuals matter. Impersonal views are 
perfectly compatible with a welfarist view, and in fact some types of impersonal approaches are compatible with different conceptions of what sort of things are valuable (such as positive experiences, satisfying preferences, a list of objective values). What Impersonal Views claim is simply that individuals' interests matter depending on how much value they contribute to an outcome. Accordingly, among some of the most common ones include

Impersonal Maximizing Total Views: the best outcome is the one with the greatest aggregation of positive minus negative welfare (Temkin 2012: Ch. 2). ${ }^{2}$

Now, typically, Narrow-Person Affecting Views have been understood so that these views will favour the prioritization of the interests of the couple in The Happy Child (Narveson 1973, Roberts 2011, Frick 2014). For their part, Impersonal Views are appealed to in order to defend the claim that in The Wretched Child the interests of the possible child should be taken into account as much as those of the couple (Persson 2009, Grill 2017). The problem for Narrow Person-Affecting Views is that they also imply that the interests of the couple should be prioritized in The Wretched Child. If this were not the case, it seems reasonable to assume that we would have the same reasons for taking the possible child's interests into account in The Happy Child (Holtug 2010: 249).

Impersonal Views are typically believed to imply that in The Wretched Child the interests of any possible child should be taken into account as much as those of the couple. Even so, these positions are more intuitive than Narrow PersonAffecting ones only on certain versions of The Wretched Child. Consider this variation of the original case

The Wretched Child 2. All remains as in The Wretched Child 1, except that the total value of the outcome where the couple have the child will be larger than the value of the outcome where they do not, because the happiness they obtain is greater than the suffering of the child.

Figure 3. The Wretched Child 2
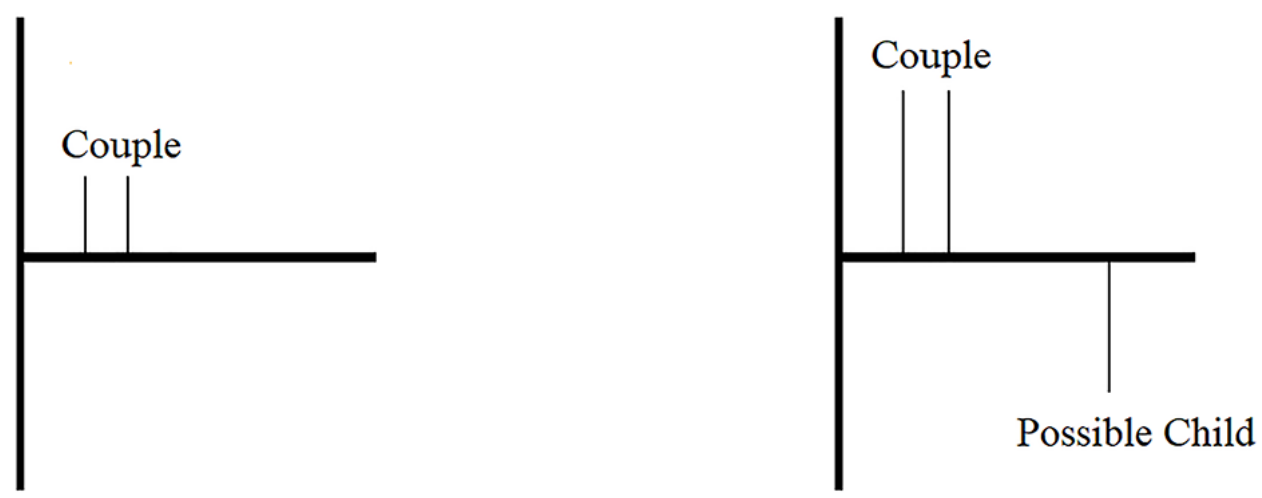

In this new variant, Impersonal Views conclude, as do Person-Affecting ones, that it is not worse if the couple have the child, which is still very counterintuitive.

In order to examine whether an alternative view to the positions we have assessed thus far can exist, in the next two sections I will consider different ways of responding to the ideas behind the trade-offs at stake in The Happy Child and the two variations of The Wretched Child. 


\section{Symmetry and Asymmetry between Positive and Negative Value}

The difference in most people's intuitions towards bringing into existence happy and unhappy lives has sometimes been known in the literature in reproductive and population ethics as "the asymmetry" (Persson 2009, Roberts 2011, Algander 2012, Frick 2014, Grill 2017). However, this term has been utilized with a different meaning as well, that is, to name the view that what makes lives valuable does not count exactly as much as what makes lives disvaluable.

Those who support this view accept

Asymmetry between Positive and Negative Value: given a correlation between the intensity and the duration of a value and a disvalue, disvalue outweighs value and thus should be given greater consideration when assessing outcomes.

However, others have appealed to a different view, known as

Symmetry between Positive and Negative Value: when assessing a situation, equal amounts of value and disvalue carry the same weight.

By and large, if we accept the Asymmetry between Positive and Negative Value (from now on, "Asymmetry") we will hold that disvalue carries greater weight than value (Mayerfeld 1996, 1999, Vinding 2020). The extent of Asymmetry will depend on how our specific view configures it. According to Lexical Asymmetrical Views no amount of value can be as significant as some amount of disvalue (that is, there is no possible correlation between value and disvalue). Some of these views are Fully Asymmetrical Views, according to which we only have reasons to reduce negative value, and not to promote positive value. This may be claimed for axiological reasons (by holding that there is no such thing as intrinsically positive value) or for normative reasons (by holding that regardless of whether intrinsically positive value does exist, we should not be concerned about promoting it, unlike what happens with negative value). Weighted Asymmetrical Views differ in that they imply that value counts less than disvalue but that value may still be given some consideration. How much less consideration will depend on how asymmetrical the view claims value and disvalue are, as well as on the normative structure of the theory (Mayerfeld 1999, Temkin 2012: Ch. 2). ${ }^{3}$ For instance, Maximizing Weighted Asymmetrical Views will support promoting positive value, although they will regard this as considerably less important than preventing negative value. But other views, such as some Deontological Weighted Asymmetrical Views and Satisficing Consequentialist Weighted Asymmetrical Views may imply that we have normative reasons to prevent negative value, but not to promote positive value.

The distinction between Symmetrical and Asymmetrical Views allows us to examine the conflict between our intuitions toward the three cases presented above in a new light, beyond the appeal to either Person-Affecting or Impersonal Views. Usually, those who accept the Symmetry between Positive and Negative Value (from now on, "Symmetry") are against procreating in order to bring into existence The Happy Child but are in favour of not procreating in cases like The Wretched Child and The Wretched Child 2. ${ }^{4}$ However, if we hold Symmetry plus an intuition against bringing into existence The Happy Child, we cannot appeal to a duty against creating wretched lives since this would be inconsistent. This is because in one instance we would not allow the trade-off that clearly seems better for the 
individuals involved (the possible happy child), ${ }^{5}$ but in the other instance we would allow the trade-off that clearly seems better for the individuals involved (the possible wretched child). As I have claimed, this is a problem for both Person-Affecting and Impersonal Maximizing Views. In particular, Impersonal Maximizing Views give us reasons to prevent The Wretched Child 1, but not The Wretched Child 2 from existing. Instead, those accepting Asymmetric Views can avoid this unwelcome implication. They will reject bringing into existence both The Wretched Child 1 and The Wretched Child 2. In addition, they do not need to accept that we should bring into existence The Happy Child. Fully Asymmetrical Views, as well as a number of Weighted Asymmetrical Views such as the Deontological or Satisficing ones we have considered, would reject that we have reasons to create The Happy Child in any case. That is, they would accept this even under an unrealistic idealizing condition according to which bringing the Happy Child into existence would not cause any disvalue at all. Other Asymmetric Views would be compatible with accepting the creation of The Happy Child only under this unrealistic condition. But they would reject it in the real world, where in all likelihood the creation of the Happy Child, as described, would come at the cost of greater suffering, and such suffering would not be compensated by the increase in positive value. Instead, this would not make any difference for Symmetric Views; they would face the dilemmas presented above both under idealized and realistic conditions.

So, to summarize, we have the following possibilities:

(1) Accept Symmetry and that we should bring into existence The Happy Child but give up our intuition against doing it.

(2) Accept Symmetry and reject that we should bring into existence The Happy Child but give up our intuition against causing The Wretched Child 2 to exist.

(3) Accept Symmetry and all our intuitions regarding The Happy Child and The Wretched Child 2, but accept inconsistency.

(4) Accept Asymmetry.

The worst option seems to be (3). Accepting an inconsistent morality would force us to face a myriad of immense complications, the most obvious one being that all of our moral beliefs cannot be correct or held together. Possibility (2) is consistent, but many of us would likely deem it to be the second worst option, given that it would not just reduce happiness, but would in addition increase suffering. Possibility (1) is consistent although it requires us to give up a very strong intuition. Lastly, possibility (4) allows us to keep our intuitions without being inconsistent. If there is Asymmetry between Positive and Negative Value, we might have a duty to avoid creating disvaluable lives but not a duty to create valuable ones. This would be the case both in person-affecting terms and in impersonal ones. Even if these views might differ in other instances, as long as such Asymmetrical views give adequate consideration to negative value, it would follow that we ought to give priority to the interests of the possible children in The Wretched Child and The Wretched Child 2 whilst we would not be required to act in such a way in The Happy Child. This would be due to the marginal relevance of positive value in comparison with negative value.

Furthermore, it can be argued that Asymmetry not only backs the intuitive solutions to this reproductive dilemma but it also can be defended on further, independent, grounds. Many people, for instance, consider it more important to 
reduce a great burden carried by someone than to help improve the situation of someone who is already faring well. Also, many consider it wrong to harm an innocent individual so that others may enjoy more pleasure, even if such pleasure is substantial (Vinding 2020). ${ }^{6}$ Practical considerations might make Asymmetry preferable to Symmetry, insofar that these considerations show that the practical effects of accepting Asymmetry may be better than those of maintaining Symmetry. One such consideration consists in the fact that we become accustomed to pleasurable experiences but not to harming ones. Another consideration would be based in the substantial amounts of suffering in the world (outweighing pleasure in many cases). As a result, the decrease of marginal positive utility is not mirrored by a decrease in marginal negative disutility. That is, resources invested in increasing pleasure become progressively less effective, whereas this does not occur in the case of reducing suffering. All these normative and factual reasons provide solid independent grounds to consider Asymmetry a sound position.

\section{Conclusion}

This paper has tried to shed new light on a difficult issue in the realm of population and reproductive ethics. Much of the philosophical literature has centred this debate around Narrow Person-Affecting Views and Impersonal Views. Instead, I considered the possibility of centring the question around Symmetry and Asymmetry, and pointed out how these views fit our intuitions regarding the dilemmas of The Happy Child and The Wretched Child (1 \& 2). Since many people's intuitions are not compatible with a consistent symmetrical position, and other positions forced us to abandon important intuitions or desired features of our views, I suggested that we should accept Asymmetry. Finally, I defended Asymmetry on further, independent grounds. More work is needed to examine how this approach would deal with other problems in reproductive, population and general ethics. However, this paper has argued that there are grounds to consider this view a sound candidate as an adequate theory for the task.

\section{Notes}

${ }^{1}$ Wide Person-Affecting Views, in contrast with narrow ones, evaluate outcomes by considering how the individuals in those outcomes fare but do not grant special consideration to how any particular individuals fare in one outcome relative to how those very same individuals fare in any alternative outcomes. It is not necessary here to explain these views in detail, but it may be pointed out that their implications would be similar to those of Impersonal Views. However, they have scarcely been examined in the philosophical literature, due to which I will, for the sake of simplicity, focus here exclusively on Impersonal Views as the alternative to Narrow Person-Affecting Views.

${ }^{2}$ This is due to the fact that, as Temkin claims, we intuitively think that quantity matters when assessing outcomes, even though its relevance might be outweighed in some instances.

${ }^{3}$ For instance, imagine that I obtain pleasure by inflicting considerable physical pain on myself, and I think the pain is worth the gain for me. If there is an Asymmetry between value and disvalue, inflicting this pain on myself might be negative or not, depending on how asymmetrical value and disvalue are. This could 
be due to several reasons. For example, it might mean that value and disvalue are incommensurable, and thus value and disvalue cannot be weighted using the same scale (Temkin calls this property discontinuity). Thus, if we give priority to disvalue and there is discontinuity, no amount of value compensates even the tiniest imaginable amount of disvalue. However, since this would be very counterintuitive in certain instances (e.g. trading a mild headache for an eternity in heaven) we may want to hold a less rigid Asymmetry and allow correlations and trade-offs between value and disvalue even when giving disvalue more weight.

${ }^{4}$ This is because most of us consider the person-affecting restriction intuitive for cases where value is involved but not for cases where disvalue is involved.

${ }^{5}$ I use the qualification "possible" here to mean that the child is not an actual individual, in order to highlight the modal difference between the couple and the child. We know all the relevant facts about the life of the child and the couple when assessing The Happy Child, The Wretched Child and The Wretched Child 2.

${ }^{6}$ This intuition is represented in various contexts. One example is the literary work The Ones that Walk Away from Omelas.

\section{References}

Algander, P. (2012) "A defence of the asymmetry in population ethics", Res Publica,18, 145-157. https://doi.org/10.1007/s11158-011-9164-0

Arrhenius, G. (2000) "An impossibility theorem for welfarist axiologies", Economics and Philosophy, 16, 247-266. https://doi.org/10.1017/ s0266267100000249

Arrhenius, G. (2009) "Can the person affecting restriction solve the problems in population ethics?" in David Wasserman \& Melinda Roberts (eds.), Harming Future Persons, Amsterdam: Springer, 289-314. https://doi.org/ 10.1007/978-1-4020-5697-0_14

Arrhenius, G. (2003) "The person affecting restriction, comparativism, and the moral status of potential people", Ethical Perspectives, 10, 185-195. https://doi.org/10.2143/EP.10.3.503884

Arrhenius, G. \& Rabinowitz, W. (2010) “Better to be than not to be?" in Hans Joas \& Barbro Klein (eds.), The benefit of broad horizons: intellectual and institutional preconditions for a global social science: festschrift for Bjorn Wittrock on the occasion of his 65th birthday, vol. 24, Boston: Brill, 65-85. http://eprints.lse.ac.uk/id/eprint/54543 [accessed on 09 October 2020].

Benatar, D. (2006) Better never to have been: the harm of coming into existence, New York: Oxford University Press. https://doi.org/10.1093/acprof:oso/ 9780199296422.001.0001

Frick, J. D. (2014) Making people happy, not making happy people: a defense of the asymmetry intuition in population ethics, $\mathrm{PhD}$ dissertation, Cambridge: Harvard University. http://nrs.harvard.edu/urn-3:HUL.InstRepos: 13064981

Griffin, J. (1979) "Is unhappiness morally more important than happiness?", The Philosophical Quarterly, 29, 47-55. https://doi.org/10.2307/2219182

Grill, K. (2017) "Asymmetric population axiology: deliberative neutrality delivered”, Philosophical Studies, 174, 219-236. https://doi.org/10.1007/ s11098-016-0678-3

Holtug, N. (2010) Persons, interests, and justice, Oxford: Oxford University Press. 
Horta, O. (2014) "In defense of the internal aspects view: person-affecting reasons, spectrum arguments and inconsistent intuitions", Law, Ethics and Philosophy, 2, 91-111. https://www.raco.cat/index.php/LEAP/article/ view/297559 [accessed on 09 October 2020].

Le Guin, U. K. (1973) The ones that walk away from Omelas, USA: New Dimensions 3. https://www.utilitarianism.com/nu/omelas.pdf [accessed on 13 November 2020].

Mayerfeld, J. (1996) “The moral asymmetry of happiness and suffering", The Southern Journal of Philosophy, 34, 317-338. https://doi.org/10.1111/ j.2041-6962.1996.tb00795.x

Mayerfeld, J. (1999) Suffering and moral responsibility, Oxford: Oxford University Press.

Mcmahan, J. (1981) "Problems of population theory", Ethics, 92, 96-127. https://doi.org/10.1086/292301

Menzel, C. (2018) “Actualism” in Edward N. Zalta (ed.), The Stanford Encyclopedia of Philosophy, https://plato.stanford.edu/archives/sum2018/entries/actualism/ [accessed 07 June 2020].

Narveson, J. (1973) "Moral problems of population", The Monist, 57, 62-86. https://doi.org/10.5840/monist197357134

Parfit, D. (1984) Reasons and persons, Oxford: Oxford University Press.

Parfit, D. (2017) "Future people, the non-identity problem, and person-affecting principles" Philosophy and Public Affairs, 45, 118-157. https://doi.org/ 10.1111/papa.12088

Persson, I. (2001) "Equality, priority and person-affecting value", Ethical Theory and Moral Practice, 4, 23-39. https://doi.org/10.1023/A:1011486120534

Persson, I. (2009) "Rights and the asymmetry between creating good and bad lives". In Melinda A. Roberts and David T. Wasserman (eds.), Harming Future Persons. Netherlands: Springer. 29-48. https://doi.org/10.1007/978-14020-5697-0

Roberts, M. A. (2011) “An asymmetry in the ethics of procreation" Philosophy Compass, 6, 765-776. https://doi.org/10.1111/j.1747-9991.2011.00435.x

Singer, P. (1979) Practical ethics, Cambridge: Cambridge University Press.

Smart, R. N. (1958) "Negative utilitarianism", Mind, 67, 542-543. https://doi.org/ 10.1093/mind/LXVII.268.542

Temkin, L. (1993) Inequality, Oxford: Oxford University Press.

Temkin, L. (2012) Rethinking the good: moral ideals and the nature of practical reasoning, Oxford: Oxford University Press.

Temkin, L. (2014) "Rethinking the good - a small taste", Law, Ethics and Philosophy, 2, 58-86. https://www.raco.cat/index.php/LEAP/article/ view/ 297557 [accessed on 09 October 2020].

Valentine, S. S. (1999) "Wrongful life, procreative responsibility, and the significance of harm", Legal Theory, 5, 117-148. https://doi.org/10.1017/ S1352325299052015

Vinding, M. (2020) Suffering-focused ethics: defense and implications, Copenhagen: Ratio Ethica. https://www.smashwords.com/books/view/874692 [accessed on 19November 2020].

Woodward, J. (1986) "The non-identity problem", Ethics, 96, 804-831. https://doi.org/10.1086/292801 